\title{
Vertical relations and number of channels in quality-differentiated markets
}

\author{
Emanuele BACCHIEGA*1 and Olivier BONROY ${ }^{\dagger} 23$ \\ ${ }^{1}$ Dipartimento di Scienze Economiche, Università di Bologna, 40126 Bologna, Italy. \\ ${ }^{2}$ INRA, UMR 1215 GAEL, F-38000 Grenoble, France \\ ${ }^{3}$ Université Grenoble 2, UMR 1215 GAEL, F-38000 Grenoble, France
}

May 2012

\begin{abstract}
Double marginalization causes inefficiencies in vertical markets. This paper argues that such inefficiencies may be beneficial to final consumers in markets producing vertically differentiated goods. The rationale behind this result is that enhancing efficiency in high-quality supply chains through vertical integration may drive out of the market low-quality ones, thus affecting market structure. As a consequence, restoring-efficiency vertical integration may reduce consumer surplus, even in the absence of foreclosure strategies by the newly integrated firms. From a policy standpoint, our paper suggests that input and/or customer foreclosure should not be considered as the only source of antitrust concern when assessing the effects of vertical integration.
\end{abstract}

Keywords: Vertical product differentiation, Vertical integration, Buyer power.

JEL classification: L13, L22, L4.

\footnotetext{
${ }^{*}$ E-mail: emanuele.bacchiega@unibo.it

${ }^{\dagger}$ Corresponding author. INRA, Université Grenoble 2, UMR 1215 GAEL, Domaine universitaire, BP 47, 38040 Grenoble Cedex 9, France. E-mail: olivier.bonroy@grenoble.inra.fr.
} 


\section{Introduction}

Vertical relations among firms are usually characterized by the "double marginalization" problem, which, by distorting input and product prices, reduces the efficiency of the supply chain. Vertical integration (or the use of efficient contracts) is a means to solve this efficiency issue. By merging in a unique firm, vertically related ones internalize the vertical externality, and restore efficiency. This is usually deemed to bring about welfare gains (Spengler, 1950). The concerns about vertical integration, by contrast, are usually associated with the fear of vertical foreclosure. ${ }^{1}$ Indeed, the newly integrated firm may decide to deny the access to its input, or to its customers, to the non-integrated rivals, so as to raise their costs or reduce their revenues. As a consequence, the literature has devoted most of its effort to delve into the economics of foreclosure. ${ }^{2}$ Recently, however, Avenel (2008) argues that foreclosure is not necessarily a driver of integration for firms, and concludes that "[successive oligopoly models] may well have exaggerated the importance of the foreclosure issue" (Avenel, 2008, p.259).

This paper analyzes the effects of vertical integration in vertically differentiated markets characterized by the so-called finiteness property. We show that in such markets the efficiency gains following vertical integration in high-quality supply chains may drive low-quality supply chains out of the market, even in absence of foreclosing strategies by the newly integrated firms. This modifies market structure and may ultimately entail a consumer surplus decrease. In addition, we argue that, in these situations, integration in the low-quality supply chains is not an effective tool to avoid exit of the low-quality channel. Our findings have direct policy implications. In fact, they suggest that the within-chain efficiency gains due to integration may reduce competition to the detriment of consumers. As a consequence, input and/or customer foreclosure is not necessary to trigger antitrust concerns in the case of vertical integration, because consumers may be harmed even in its the absence. Stated differently, we find that some extent of vertical externality may a have positive effect on consumer surplus because it fosters competition by preventing the exit of low-quality firms.

The finiteness property (Gabszewicz and Thisse, 1979; Shaked and Sutton, 1983) is one of the major outcomes of the analysis of vertically differentiated markets. This property establishes

\footnotetext{
${ }^{1}$ See, e.g. OECD (2007).

${ }^{2}$ For theoretical analyses about vertical mergers and foreclosure see e.g. Salinger (1988), Hart and Tirole (1990), Ordover et al. (1990), Salinger (1991), Church and Gandal (2000), and Chen (2001).
} 
that, if unit variable cost "do not increase too steeply in quality", the number of firms with a positive market share is finite and depends on the degree of heterogeneity of consumers. This has direct effects on the variety of products available for consumption, because, once the maximum number of firms is reached, further entry may occur only with higher-quality variants, with lower-quality ones exiting, so as to keep constant the total number of products.

The basic mechanism at work in the present paper is the following. When firms are not integrated (and do not use efficient negotiation schemes), transfer prices in the supply chains do not reflect marginal production costs. This has a twofold effect on consumers. On the one hand, a transfer price greater than marginal cost is detrimental for consumers since it generates higher equilibrium prices. On the other hand, downstream firms are less aggressive because of higher input costs. This results in a higher number of products that may have positive demands at equilibrium, and, thus, on the number of supply chains actually operating in the market. This ultimately results in a "fierce" market competition, which increases consumer surplus. By contrast, vertical integration (or the use of efficient production schemes), reduces downstream firms' costs, thus making them more aggressive. As a consequence, the lower-quality channels may exit the market in the presence of any arbitrarily small fixed cost of production. This reduces the number of operating firms and, therefore, the competitive pressure in the market, and may more than offset the efficiency gains obtained within the high-quality supply chain.

To make our point we set up and solve a simple model of vertical product differentiation with two supply chains made of an upstream and a downstream firm each. Exchange takes place within the supply chain only. Each upstream firm sells an input to its downstream counterpart. This firm transforms the input into a consumption good and sells it to the final consumers. The quality of the input determines the quality of the output. ${ }^{3}$ The marginal production costs are zero for both the upstream and downstream firm, whereas the transfer price in each supply chain is obtained through a bargaining process between the upstream and downstream firms. ${ }^{4}$ We find the region in the parameter space where the market can support at most the highquality firm. ${ }^{5}$ We show that the size of this region depends on the bargaining weights within the high-quality supply channel, and that this region is included in the one obtained in the case of vertical integration in the high-quality supply chain. This allows us to conclude that vertical

\footnotetext{
${ }^{3}$ See, e.g. Gabszewicz and Turrini (2000) and Bonroy and Lemarié (2012)

${ }^{4}$ At the end of Section 3, we discuss the effect of asymmetric marginal production costs on our analysis.

${ }^{5}$ The market is preempted, in the taxonomy of Wauthy (1996).
} 
integration at the high-quality end of the market may lead supply chains active at the low-end to exit. We finally show that this may reduce consumer surplus.

Our paper deals with the analyses on vertical relationships and product differentiation (see e.g. Choi and Yi, 2000; Pepall and Norman, 2001; Belleflamme and Toulemonde, 2003; Avenel and Caprice, 2006; Matsuhima, 2009; Bonroy and Lemarié, 2012). More specifically, this work relates to literature on vertical integration and quality, and on buyer power and differentiation. Several works have explored the effects of vertical integration on quality choice. Economides (1999) shows that independent vertically-related monopolists provide products of lower quality level than an integrated monopolist. Further, under integrated monopoly, market coverage, consumer surplus and profits are higher than in the non-integrated case. Recently, HernánGonzález and Kujal (2012) and Zenger (2009) have established an opposite result, in that they show that vertical integration may drive to lower quality on the market. Differently from this literature, we focus on the effect of vertical integration on the number of operating supply channels, rather than on quality choice for a given number of supply chains. ${ }^{6}$

The literature on buyer power generally deals with horizontally differentiated products (see e.g. Inderst and Shaffer, 2007). Few papers consider vertical product quality. A recent relevant exception is Chambolle and Villas-Boas (2008), that focuses on vertically differentiated chains in which each pair of retailers and producers bargains over the terms of the exchange. The authors show that retailers may have interest to quality-differentiate their product even if they operate in downstream segmented markets where they are monopolists. Indeed, in doing so, they improve their own buyer power relative to the upstream supplier. This paper abstracts from downstream competition and the effects of vertical integration, which are, by contrast, at the core of the present paper.

The paper is organized as follows. Section 2 presents our basic model and characterizes its equilibrium. Section 3 analyzes the effects of vertical integration. Finally, Section 4 puts our results into perspective and provides a short conclusion.

\footnotetext{
${ }^{6}$ More broadly, this paper also relates literature examining the relationship between inter-channel linkages and market structure (Lewis and Yildirim, 2002; Biglaiser and Vettas, 2004; Clark and Polborn, 2011).
} 


\section{The model}

We study two supply chains selling products of different qualities to a population of consumers. Each supply chain is characterized by an upstream firm and a downstream firm. We assume that one unit of input is required to produce one unit of output, and that the quality of the final product is determined by the quality of the input. Upstream firm $i, i=1,2$, produces at zero cost an input of quality $s_{i}$ and sells it at a price $w_{i}$, to its downstream partner. This, in turn, sells the final good to consumers at price $p_{i}$. We assume that $s_{2}>s_{1}$, therefore, the supply chain 2 is the quality leader. Following Mussa and Rosen (1978), a consumer enjoys an indirect utility $U(\theta)=\theta s_{i}-p_{i}$ if she buys a product of quality $s_{i}$ sold at a price $p_{i}$, and zero if she refrains from buying. Consumers differ in their quality appreciation $\theta$, which is uniformly distributed with density $\frac{1}{\bar{\theta}-\theta}$ over $[\underline{\theta}, \bar{\theta}]$, with $\underline{\theta}>0$. The standard marginal consumer approach allows to define market demands as follows.

$$
\left\{\begin{array}{l}
D_{1}\left(p_{1}, p_{2}\right)=\frac{1}{\bar{\theta}-\underline{\theta}}\left(\frac{p_{2}-p_{1}}{s_{2}-s_{1}}-\frac{p_{1}}{s_{1}}\right), \\
D_{2}\left(p_{1}, p_{2}\right)=\frac{1}{\bar{\theta}-\underline{\theta}}\left(\bar{\theta}-\frac{p_{2}-p_{1}}{s_{2}-s_{1}}\right) .
\end{array}\right.
$$

As in a standard vertical differentiation model, three market configurations may arise at the price sub-equilibrium, namely uncovered, covered and preempted market. In the first case $\frac{p_{2}-p_{1}}{s_{2}-s_{1}}>\frac{p_{1}}{s_{1}}>\underline{\theta}$, in the second $\frac{p_{2}-p_{1}}{s_{2}-s_{1}}>\underline{\theta} \geq \frac{p_{1}}{s_{1}}$, and, in the third, $\underline{\theta} \geq \frac{p_{2}-p_{1}}{s_{2}-s_{1}}>\frac{p_{1}}{s_{1}} \cdot{ }^{7}$

In the following, we shall focus on the covered market configuration with interior solution. In this case downstream prices are such that

$$
\frac{p_{2}-p_{1}}{s_{2}-s_{1}}>\underline{\theta}>\frac{p_{1}}{s_{1}}
$$

and, accordingly, demands are written as:

$$
\left\{\begin{array}{l}
D_{1}\left(p_{1}, p_{2}\right)=\frac{1}{\bar{\theta}-\underline{\theta}}\left(\frac{p_{2}-p_{1}}{s_{2}-s_{1}}-\underline{\theta}\right), \\
D_{2}\left(p_{1}, p_{2}\right)=\frac{1}{\bar{\theta}-\underline{\theta}}\left(\bar{\theta}-\frac{p_{2}-p_{1}}{s_{2}-s_{1}}\right) .
\end{array}\right.
$$

We model a two-stage game that unfolds as follows. At stage 1, the upstream and downstream suppliers within each chain bargain over the upstream prices. At stage 2, downstream firms set

\footnotetext{
${ }^{7}$ See Wauthy (1996).
} 
the prices of their variants on the final market. We solve the game backwards to obtain subgameperfect Nash equilibria.

As a first step, we find the equilibrium in the final market for given $w_{1}$ and $w_{2}$. Standard computations yield the following prices.

$$
p_{1}^{*}=\frac{\bar{\theta}-2 \underline{\theta}}{3}\left(s_{2}-s_{1}\right)+\frac{w_{2}+2 w_{1}}{3} \text { and } p_{2}^{*}=\frac{2 \bar{\theta}-\underline{\theta}}{3}\left(s_{2}-s_{1}\right)+\frac{2 w_{2}+w_{1}}{3} .
$$

Let us now tackle the upstream price game. We use the Nash bargaining solution (see Nash, 1950; Kalai, 1977) to obtain the upstream prices $w_{i}$ for $w_{j}$, with $i, j \in(1,2)$ and $i \neq j$. We assume that if no transaction takes place, then downstream firms cannot produce any good and upstream firms may sell on a spot market at marginal cost, thus the outside option for all firms is zero. Accordingly, the Nash products are written as follows

$$
\begin{aligned}
& B_{1}\left(w_{1}\right)=\pi_{1}\left(w_{1}\right)^{\mu} \Pi_{1}\left(w_{1}\right)^{1-\mu}, \\
& B_{2}\left(w_{2}\right)=\pi_{2}\left(w_{2}\right)^{\nu} \Pi_{2}\left(w_{2}\right)^{1-\nu},
\end{aligned}
$$

where $\pi_{i}$ (res. $\Pi_{i}$ ) the downstream (res. upstream) firm $i$ 's profit, and $\nu$ (res. $\mu$ ) represents the bargaining power of the high-quality (res. low-quality) downstream firm in the bargaining game. Note that when $\nu=1$ the Nash bargaining solution of (6) coincides with the transfer price set by the high-quality downstream firm if it were backwards integrated with the supplier. Symmetrically, when $\nu=0$, the Nash bargaining solution of (6) coincides with the transfer price set by the upstream firm if it were endowed with full monopoly power over the downstream firms. ${ }^{8}$ Maximization of (5) and (6) yields the upstream prices in the two supply chains, which are, respectively

$$
\begin{aligned}
& w_{1}=\frac{1-\mu}{2}\left(w_{2}+\left(s_{2}-s_{1}\right)(\bar{\theta}-2 \underline{\theta})\right), \\
& w_{2}=\frac{1-\nu}{2}\left(w_{1}+\left(s_{2}-s_{1}\right)(2 \bar{\theta}-\underline{\theta})\right) .
\end{aligned}
$$

By solving the system defined by (7) and (8) we obtain the equilibrium upstream prices, which

\footnotetext{
${ }^{8}$ The Nash bargaining solution is a concise tool to impose a wedge between marginal production cost and transfer price within the chain without any specific assumption on distribution of market power between upstream and downstream firms.
} 
may be plugged back into (4) to obtain the equilibrium downstream prices. They are, respectively:

$$
\left\{\begin{array} { l } 
{ w _ { 1 } ^ { * } = ( 1 - \mu ) \Delta , } \\
{ w _ { 2 } ^ { * } = ( 1 - \nu ) \Lambda , }
\end{array} \text { and } \left\{\begin{array}{l}
p_{1}^{*}=\frac{2}{3}(2-\mu) \Delta \\
p_{2}^{*}=\frac{2}{3}(2-\nu) \Lambda
\end{array}\right.\right.
$$

with $\Delta \equiv \frac{\left(s_{2}-s_{1}\right)(2 \bar{\theta}(2-\nu)-\underline{\theta}(5-\nu))}{3+\mu+\nu-\mu \nu}$ and $\Lambda \equiv \frac{\left(s_{2}-s_{1}\right)(\bar{\theta}(5-\mu)-2 \underline{\theta}(2-\mu))}{3+\mu+\nu-\mu \nu}$.

Note that these values have been obtained under the assumption of covered market with interior solution. We shall, therefore, identify the parameters constellations for which (9) indeed define such an equilibrium. By plugging (9) back into (2) and rearranging terms we obtain that, at equilibrium, the market is covered with an interior solution for:

$$
\left.\frac{\bar{\theta}}{\underline{\theta}} \in\right] \frac{(5-\nu)}{2(2-\nu)}, \Phi[
$$

with $\Phi \equiv \frac{2 s_{2}(2-\mu)(5-\nu)-s_{1}(11-7 \nu+\mu(-13+5 \nu))}{4\left(s_{2}-s_{1}\right)(2-\mu)(2-\nu)}>\frac{5-\nu}{2(2-\nu)}, \forall(\mu, \nu) \in[0,1]^{2}$ and $s_{2}>s_{1}$.

Note that for $\nu=\mu=1$, both equilibrium prices $p_{i}^{*}$ and condition (10) boil down to those in Wauthy (1996).

It is easy to ascertain that for all

$$
\left.\underline{\bar{\theta}} \in] 1, \frac{(5-\nu)}{2(2-\nu)}\right]
$$

firm 2 only enjoys a positive market share at equilibrium (the market is preempted). In the same way, the parameter conditions may be determined, such as at equilibrium the market is uncovered or covered with corner solution (see Appendix A).

We are now in a position to state a first result on the effect of vertical relationships in a standard vertically differentiation model.

Lemma 1 The number of products which have a positive market share at equilibrium depends on both the heterogeneity of consumers $[\underline{\theta}, \bar{\theta}]$ and the distribution of bargaining power in the high-quality supply channel $(\nu)$.

As in a standard vertically differentiated model, the number of products which have a positive market share at equilibrium depends on both the heterogeneity of consumers $[\underline{\theta}, \bar{\theta}]$ (see Gabszewicz and Thisse, 1979; Shaked and Sutton, 1982). In addition, our analysis points out 
that the number of products surviving at equilibrium also depends on the distribution of bargaining power in the high-quality supply channel. Finally, and more surprising, we show that the distribution of bargaining power in low-quality chain does not play any role in the survival of the low-quality product.

\section{Vertical integration and the number of products}

Lemma 1 shows that the number of products depends on the distribution of bargaining power in the high-quality chain, and in particular on the relative power of the high-quality downstream firm $(\nu)$. It is a matter of calculations to show that the upper bound of condition (11) is monotonically increasing in $\nu$ and is equal to 2 for $\nu=1$. As mentioned above, the case $\nu=1$ corresponds to the situation where the high-quality channel is integrated. Hence, vertical integration drives out the market the low-quality product for all

$$
\left.\left.\frac{\bar{\theta}}{\underline{\theta}} \in\right] \frac{(5-\nu)}{2(2-\nu)}, 2\right]
$$

This suggests that, while vertical integration is generally deemed good for consumers because it rules out double marginalization, it may also harm them by reducing the number of variants actually available on the market.

To delve into this point, we modify our model as follows. Assume that the downstream firms may enter the market by paying a positive and arbitrarily small $\operatorname{cost} \varepsilon \rightarrow 0$. If a downstream firm enters the market, it enters in an exclusive vertical relation with one upstream supplier, and the downstream firm may decide whether or not integrate backwards with its upstream supplier. ${ }^{9}$ If integration occurs the upstream price equals marginal production cost, else Nash bargaining takes place. Finally prices are set. If one firm does not enter, it receives payoff equal to zero. ${ }^{10}$ Let us focus on the case where $\left.\left.\frac{\bar{\theta}}{\underline{\theta}} \in\right] \frac{(5-\nu)}{2(2-\nu)}, 2\right]$. As pointed out above, in this parameter region, vertical integration in the high-quality supply chain does not allow for a positive demand for the low-quality product. As a consequence, the low-quality downstream firm does not enter the market if it anticipates that the rival firms would integrate. Thus the integrated high-quality

\footnotetext{
${ }^{9}$ We rule out here credit constraints for the downstream firms.

${ }^{10} \mathrm{We}$ assume that upstream firms are always present on the market. This the case when there exists an alternative spot market, where they can sell their input at marginal cost.
} 
firm only would be on the market, and the sub-game perfect Nash equilibrium would coincide with the monopoly outcome given by: ${ }^{11}$

$$
p_{2}^{i}=\underline{\theta} s_{2} \text { and } D_{2}\left(p_{2}^{i}\right)=1 .
$$

We may now establish:

Proposition 1 For all $\left.\left.\frac{\bar{\theta}}{\underline{\theta}} \in\right] \frac{(5-\nu)}{2(2-\nu)}, 2\right]$, i) the high-quality downstream firm always finds it profitable to integrate backwards, ii) integration in high-quality chain reduces the number of products which can survive at equilibrium, and iii) consumers are harmed by integration for $s_{1} \in\left[\widetilde{s}_{1}, s_{2}\right]$.

\section{Proof. See Appendix B.}

The intuition for the reduction in consumer surplus is as follows. When the high-quality supply chain is not integrated, two forces contribute to determine the consumer surplus. The first one derives from the fact that transfer prices for the high-quality product are higher than marginal production costs, which makes the price of the high-quality variant to increase. By strategic complementarity, the price of the low-quality variant increases as well. This effect clearly harms consumers. The second derives by the presence of two supply chains operating in the market. This triggers competition, whose extent inversely depends on the degree of product differentiation. A higher $s_{1}$, for given $s_{2}$, makes variants more homogeneous, thus increasing competition. The level of competition has also a feedback effect on transfer prices. Indeed, harsher competition reduces the size of the chain's profits to be shared between upstream and downstream firms, see eq. (9), which entails lower transfer prices and, therefore, lower prices. This second effect benefits consumers. When the high-quality chain is integrated the competitive effect vanishes, because this chain is monopolist for any arbitrarily small entry cost. On the other hand, however, transfer prices equal marginal production costs, which results in a lower price because of increased "supply side efficiency". When $s_{1}$ is "large enough", integration generates a large loss in consumer surplus due to the disappearing of competition, and this loss is not offset by the increase in "supply side efficiency". This observation suggests that the anticompetitive effects of vertical integration in the high-quality supply chain are more likely to be observed in

\footnotetext{
${ }^{11}$ For $\left.\left.\frac{\bar{\theta}}{\underline{\theta}} \in\right] 1,2\right]$ the monopolist covers all the market with the price $p_{2}^{m}=\underline{\theta} s_{2}$.
} 
markets regulated through Minimum Quality Standards, where the quality range is compressed (Ronnen, 1991). Furthermore, it is worth noticing that the reduction in consumer surplus is not related to a reduction in the mass of consumers that purchase one of the two variants. In fact, the total size of the demand for the differentiated good is unit both with and without integration.

One natural question that may arise from our previous analysis is to what extent the anticompetitive effect we have pointed out hinges on the simplifying hypothesis that firms have symmetric (and zero) production costs. It may be shown that the introduction of a marginal cost asymmetry between chains does not qualitatively alter our results. ${ }^{12}$ In particular, let the high-quality product have a higher marginal production cost than the low-quality one. When the cost asymmetry is "small", integration in the high-quality chain may drive out of the market the low-quality product and reduce consumer surplus. When the cost disadvantage of the highquality chain is "high", by contrast, this chain may be driven out of the market by integration in the low-quality one, with possible detrimental effects on consumer surplus. This suggests that vertical integration may lead to the exit of the chain that is the least technologically efficient relative to the quality of its product.

\section{Discussion and Conclusion}

This paper highlights a novel strategic effect of vertical integration. We show that the gains of efficiency due to the integration in the high-quality supply chain may drive out of the market the low-quality supply chain. This finding has relevant policy implications, because, if the degree of quality differentiation is sufficiently low, vertical integration harms consumers.

It is worth noticing that the potential losses in consumer surplus in our paper are not related to the choice of integrated producers to foreclose non-integrated downstream firms so as to soften price competition for the intermediate input, as in the "classical" literature on vertical foreclosure (see e.g. Ordover et al., 1990 and the references therein). Rather, vertical integration increases supply chains internal efficiency, which, in turn, fosters competition and may drive out of the market low-quality chains. For any arbitrarily small entry cost, the high-quality chain can monopolize the market, which may harm consumers. It is also instructive that both the power

\footnotetext{
${ }^{12}$ See Appendix $\mathrm{C}$ for details.
} 
buyer level and the decision whether to integrate or not within the low-quality supply chain has no influence on the survival of the low-quality variant. Accordingly, potential integration within the low-quality chain cannot be a strategic response to the integration of the high-quality channel, such as in Hart and Tirole (1990). Furthermore, our analysis suggests that consumer may be worse off even if vertical integration does not lead to lower supplied qualities as in Battigalli et al. (2007), or to a higher differentiation degree, such as in Matsuhima (2009). ${ }^{13}$

It should be remarked that the argument presented in the present paper as far as channel integration is concerned may be applied to the case where the upstream and downstream firm in the high-quality supply chain agree on efficient contracts. One clear example is that of contracts based on a two-part tariff allowing the downstream firm to purchase at marginal cost the input and remunerating the upstream firm through a lump-sum transfer (see e.g. Inderst and Shaffer, 2007).

Finally, our results are valid even the case where the market before integration is not duopolistic -at least in the easiest case of symmetric and zero marginal production costs. In fact it can be shown that the same mechanism we have highlighted for that case is at work when three chains initially compete in the market. ${ }^{14}$ In particular, integration in a higher-quality supply chain drives the lowest-quality one out of the market, which may generate losses in consumer surplus.

Our results have straightforward policy implications, because antitrust concerns about vertical integration are usually driven by the presumption that integration may lead to anticompetitive input and/or customer foreclosure by the integrated firm. We have shown that such an anti-competitive outcome may obtain even in the absence of foreclosure.

\footnotetext{
${ }^{13}$ Battigalli et al. (2007) show that an increase in buyer power may dampen welfare because it lowers the quality supplied to the market. In our paper an increase in $\nu$ is equivalent to a "more integrated" supply chain, and $\nu=1$ corresponds to full integration in the channel. In an Hotelling-type location model, Matsuhima (2009) shows that vertical integration may lead to maximal product differentiation and to higher downstream prices, which make consumers worse off.

${ }^{14}$ The three-chain model cannot be analytically solved. However, numerical examples confirm the results and intuition of Proposition 1.
} 


\section{Appendices}

\section{A SPNE equilibrium partition}

The subgame-perfect Nash equilibrium partition is as follows.

- If $\left.\frac{\bar{\theta}}{\underline{\theta}} \in\right] \frac{\left(4 s_{2}-s_{1}\right)\left(16 s_{2}^{2}+4 s_{1}^{2}-s_{2} s_{1}(17-\mu-\nu+\mu \nu)\right)}{4\left(s_{2}-s_{1}\right)\left(s_{2}(3-\mu)-s_{1}\right)\left(s_{2}(3-\nu)-s_{1}\right)}, \infty[$ the downstream market is uncovered.

- If $\frac{\bar{\theta}}{\underline{\theta}} \in\left[\frac{2 s_{2}(2-\mu)(5-\nu)-s_{1}(11-7 \nu+\mu(-13+5 \nu))}{4\left(s_{2}-s_{1}\right)(2-\mu)(2-\nu)}, \frac{\left(4 s_{2}-s_{1}\right)\left(16 s_{2}^{2}+4 s_{1}^{2}-s_{2} s_{1}(17-\mu-\nu+\mu \nu)\right)}{4\left(s_{2}-s_{1}\right)\left(s_{2}(3-\mu)-s_{1}\right)\left(s_{2}(3-\nu)-s_{1}\right)}\right]$ the downstream market is covered with a corner solution.

- If $\left.\frac{\bar{\theta}}{\underline{\theta}} \in\right] \frac{(5-\nu)}{2(2-\nu)}, \frac{2 s_{2}(2-\mu)(5-\nu)-s_{1}(11-7 \nu+\mu(-13+5 \nu))}{4\left(s_{2}-s_{1}\right)(2-\mu)(2-\nu)}[$ the downstream market is covered with an interior solution.

- If $\left.\left.\frac{\bar{\theta}}{\underline{\theta}} \in\right] 1, \frac{(5-\nu)}{2(2-\nu)}\right]$ only the high-quality product have a positive market share.

\section{B Proof of Proposition 1}

i) Let $\pi_{2}^{*}$ and $\pi_{2}^{i}$ be firm 2 ' s profits in the non-integrated and integrated environment respectively. Then the following inequality, $\pi_{2}^{i}=s_{2} \underline{\theta}>\pi_{2}^{*}=\frac{\left(s_{2}-s_{1}\right)(1+\nu)^{2}(2 \underline{\theta}(2-\mu)-\bar{\theta}(5-\mu))^{2}}{9(\bar{\theta}-\underline{\theta})(3+\mu+\nu-\mu \nu)^{2}}$, always holds for all $\left.\left.\frac{\bar{\theta}}{\underline{\theta}} \in\right] \frac{(5-\nu)}{2(2-\nu)}, 2\right]$.

ii) See Lemma 1.

iii) Let $S C \equiv \frac{1}{(\bar{\theta}-\underline{\theta})}\left(\int_{\underline{\theta}}^{\frac{p_{2}^{*}-p_{1}^{*}}{s_{2}-s_{1}}}\left(\theta s_{1}-p_{1}^{*}\right) d \theta+\int_{\frac{p_{2}^{*}-p_{1}^{*}}{s_{2}-s_{1}}}^{\overline{\bar{\theta}}}\left(\theta s_{2}-p_{2}^{*}\right) d \theta\right)$ be the consumer surplus in the non-integrated environment, and let $S C^{i} \equiv \frac{1}{(\bar{\theta}-\underline{\theta})} \int_{\underline{\theta}}^{\bar{\theta}}\left(\theta s_{2}-p_{2}^{i}\right) d \theta$ be the consumers' surplus in the integrated environment. Direct comparison reveals that $S C>S C^{i}$ for $s_{1} \in\left[\bar{s}_{1}, s_{2}\right]$;

with $\bar{s}_{1} \equiv \frac{\left(s_{2}(2 \bar{\theta}(2-\nu)-\underline{\theta}(5-\nu))(2 \bar{\theta} \Gamma+\underline{\theta}(85+31 \nu+\mu(2-34 \nu+\mu(-11+7 \nu)))\right.}{4 \bar{\theta}^{2}(2-\nu) \Gamma+\underline{\theta}^{2}\left(-263+\mu(98+73 \mu)+38 \nu+2(50-41 \mu) \mu \nu+(7-5 \mu)^{2} \nu^{2}\right)+8 \bar{\theta} \underline{\theta}(2-\mu)(2-\nu)(19+7 \nu+\mu(7-5 \nu))}$ and $\Gamma \equiv\left(-43-2 \mu+5 \mu^{2}-4(-2+\mu)^{2} v\right)$.

Now, we have prove that there always exists a positive $\bar{s}_{1}$ fulfilling the following points a) and $b)$.

a) The condition given by equation (10): $\left.\frac{\bar{\theta}}{\underline{\theta}} \in\right] \frac{(5-\nu)}{2(2-\nu)}, \frac{2 s_{2}(2-\mu)(5-\nu)-s_{1}(11-7 \nu+\mu(-13+5 \nu))}{4\left(s_{2}-s_{1}\right)(2-\mu)(2-\nu)}[$. To ascertain this, rearrange the upper bound as follows: $s_{1}>\overline{\bar{s}}_{1} \equiv \frac{2 s_{2}(2-\mu)(2 \bar{\theta}(2-\nu)-\underline{\theta}(5-\nu))}{4 \bar{\theta}(2-\mu)(2-\nu)-\underline{\theta}(11-\mu(13-5 \nu)+7 \nu)}$. It is a matter of algebra to prove that $\bar{s}_{1}>\overline{\bar{s}}_{1}$ for all $\frac{\bar{\theta}}{\underline{\theta}}>\frac{(5-\nu)}{2(2-\nu)}$. 
b) The condition that $2 \in] \frac{(5-\nu)}{2(2-\nu)}, \frac{2 s_{2}(2-\mu)(5-\nu)-s_{1}(11-7 \nu+\mu(-13+5 \nu))}{4\left(s_{2}-s_{1}\right)(2-\mu)(2-\nu)}[$, which guarantees that the set $\left.] \frac{(5-\nu)}{2(2-\nu)}, 2\right]$ given by (12) is included in the set $] \frac{(5-\nu)}{2(2-\nu)}, \Phi[$ given by (10). To see that this condition is met, rearrange the upper bound as follows $s_{1}>\overline{\bar{s}}_{1} \equiv \frac{2 s_{2}(2-\mu)(1-\nu)}{7-\mu(1-\nu)-3 \nu}$. Note that the relative size of $\bar{s}_{1}$ and $\overline{\bar{s}}_{1}$ depends on parameter values.

Therefore we may conclude that for all $\left.\left.\frac{\bar{\theta}}{\underline{\theta}} \in\right] \frac{(5-\nu)}{2(2-\nu)}, 2\right], S C>S C^{i}$ for $s_{1} \in\left[\widetilde{s}_{1}, s_{2}\right]$ with $\widetilde{s}_{1} \equiv \operatorname{Max}\left(\bar{s}_{1}, \overline{\bar{s}}_{1}\right)$. For instance, for $\mu=v=1 / 2$ the condition given by equation (10) becomes $\underline{\underline{\theta}} \in] 3 / 2, \frac{\left(6 s_{2}-s_{1}\right)}{4\left(s_{2}-s_{1}\right)}\left[\right.$. The upper bound may be rearranged as follows: $s_{1}>\overline{\bar{s}}_{1}=\frac{2 s_{2}(2 \bar{\theta}-3 \underline{\theta})}{4 \bar{\theta}-\underline{\theta}}$. Moreover we have $S C>S C^{i}$ iff $s_{1}>\bar{s}_{1}=\frac{s 2(28 \bar{\theta}-27 \underline{\theta})(2 \bar{\theta}-3 \underline{\theta})}{56 \bar{\theta}^{2}-88 \bar{\theta} \theta \underline{\theta}+31 \underline{\theta}^{2}}>0$, and $2<\frac{\left(6 s_{2}-s_{1}\right)}{4\left(s_{2}-s_{1}\right)}$ iff $s_{1}>\overline{\bar{s}}_{1}=\frac{2}{7} s_{2}$. Therefore for all $\left.\frac{\bar{\theta}}{\theta} \in\right] 3 / 2,2\left[, S C>S C^{i}\right.$ for $s_{1} \in\left[\widetilde{s}_{1}, s_{2}\right]$ with $\widetilde{s}_{1} \equiv$ $\operatorname{Max}\left(\frac{s 2(28 \overline{\bar{\theta}}-27 \underline{\theta})(2 \bar{\theta}-3 \underline{\theta})}{56 \bar{\theta}^{2}-88 \bar{\theta} \underline{\theta}+31 \underline{\theta}^{2}}, \frac{2}{7} s_{2}\right)$ and $\bar{s}_{1}-\overline{\bar{s}}_{1}=\frac{5 s 2(8 \bar{\theta}-7 \underline{\theta})(2 \bar{\theta}-3 \underline{\theta}) \underline{\theta}}{(4 \bar{\theta}-\underline{\theta})\left(56 \bar{\theta}^{2}-88 \bar{\theta} \underline{\theta}+31 \underline{\theta}^{2}\right)}>0$.

\section{Asymmetric production costs}

In this appendix we check the robustness of our results to the introduction of asymmetric marginal production costs. Without loss of generality, we let low-quality chain still have no cost of production. By contrast, a positive and constant marginal cost $c_{2}>0$ is borne -either by the upstream or by the downstream firm- within the high-quality supply chain. Note that $c_{2}$ is a technological variable, and cannot be influenced by the choice whether to integrate or not. This modification does not qualitatively alter the results of Proposition 1.

Indeed, for $c_{2}<\underline{\theta}\left(s_{2}-s_{1}\right)$, the region where integration in the high-quality chain leads to the exit of the low-quality one, given by

$$
\left.\bar{\theta} \in] \frac{(5-\nu) \underline{\theta}}{2(2-\nu)}-\frac{c_{2}(1+\nu)}{2\left(s_{2}-s_{1}\right)(2-\nu)}, 2 \underline{\theta}-\frac{c_{2}}{\left(s_{2}-s_{1}\right)}\right] .
$$

This region is decreasing in $c_{2}$.

For $c_{2} \geq \underline{\theta}\left(s_{2}-s_{1}\right)$, the region defined in (14) disappears and is replaced by one where integration in the low-quality chain may drive out of the market the high-quality one, given by:

$$
\left.\bar{\theta} \in] \frac{2(2-\mu) \underline{\theta}}{(5-\mu)}+\frac{c_{2}(1+\mu)}{\left(s_{2}-s_{1}\right)(5-\mu)}, \frac{1}{2}\left(\underline{\theta}+\frac{c_{2}}{\left(s_{2}-s_{1}\right)}\right)\right] .
$$

It may be checked that this region is increasing in $c_{2}$ for all $\mu<1$. 
This suggests that integration in chains operating in vertically differentiated markets hurts the firms that is the least technologically efficient relatively to the quality of the good it produces.

An entry game similar to that described in section 3 may be set-up. In such a game, it may be shown that integration is profitable for the more technologically efficient downstream firm and that it may harm consumers. ${ }^{15}$ Integration within the less technologically efficient channel has no effect on its survival on the market.

\section{References}

Avenel, E. (2008). "Strategic vertical integration without foreclosure". The Journal of Industrial Economics, 56(2):247-262.

Avenel, E. and Caprice, S. (2006). "Upstream market power and product line differentiation in retailing". International Journal of Industrial Organization, 24(2):319-334.

Battigalli, P., Fumagalli, C., and Polo, M. (2007). "Buyer power and quality improvements". Research in Economics, 61(2):45 - 61.

Belleflamme, P. and Toulemonde, E. (2003). "Product differentiation in successive vertical oligopolies". Canadian Journal of Economics/Revue canadienne d'économique, 36(3):523545.

Biglaiser, G. and Vettas, N. (2004). "Dynamic price competition with capacity constraints and strategic buyers". CEPR Discussion Paper 4315.

Bonroy, O. and Lemarié, S. (2012). "Downstream labeling and upstream price competition". European Economic Review, 56(3):347 - 360 .

Chambolle, C. and Villas-Boas, S. B. (2008). "Buyer power through producer's differentiation". Working paper, Department of Agricultural and Resource Economics, University of California, Berkeley, pages 1-38.

Chen, Y. (2001). "On vertical mergers and their competitive effects". RAND Journal of Economics, 32(4):667-685.

\footnotetext{
${ }^{15}$ The complexity of the equilibrium values does not allow for an analytical appraisal of the effects of integration on consumer surplus. Yet, numerical examples confirm that, in this region, if qualities are "close" integration reduces consumer surplus. Calculations are available upon request.
} 
Choi, J. P. and Yi, S.-S. (2000). "Vertical foreclosure with the choice of input specifications". The RAND Journal of Economics, 31(4):pp. 717-743.

Church, J. and Gandal, N. (2000). "Systems competition, vertical merger, and foreclosure". Journal of Economics \& Management Strategy, 9(1):25-51.

Clark, C. and Polborn, M. (2011). "Strategic buying to prevent seller exit". Journal of Economics and Management Strategy, 20(2):339-378.

Economides, N. (1999). "Quality choice and vertical integration". International Journal of Industrial Organization, 17:903-914.

Gabszewicz, J. J. and Thisse, J.-F. (1979). "Price competition, quality and income disparities". Journal of Economic Theory, 20(3):340-359.

Gabszewicz, J. J. and Turrini, A. (2000). "Workers' skills, product quality and industry equilibrium". International journal of industrial organization, 18(4):575-593.

Hart, O. and Tirole, J. (1990). "Vertical integration and market foreclosure". Brookings Papers on Economic Activity. Microeconomics, 1990:pp. 205-286.

Hernán-González, R. and Kujal, P. (2012). "Vertical integration, market foreclosure and quality investment". Portugal Economic Journal, 11:1-20.

Inderst, R. and Shaffer, G. (2007). "Retail mergers, buyer power and product variety*". The Economic Journal, 117(516):45-67.

Kalai, E. (1977). "Nonsymmetric Nash solutions and replications of 2-person bargaining". International Journal of Game Theory, 6(3):129-133.

Lewis, T. and Yildirim, H. (2002). "Managing dynamic competition". American Economic Review, 92(4):779-797.

Matsuhima, N. (2009). "Vertical mergers and product differentiation". The Journal of Industrial Economics, 57(4):812-834.

Mussa, M. and Rosen, S. (1978). "Monopoly and product quality". Journal of Economic Theory, 18(2):301-317. 
Nash, J. F. (1950). "The bargaining problem". Econometrica, 18(2):155-162.

OECD (2007). "Vertical mergers". Working Paper DAF/COMP21, OECD.

Ordover, J. A., Saloner, G., and Salop, S. C. (1990). "Equilibrium vertical foreclosure". The American Economic Review, 80(1):127-142.

Pepall, L. and Norman, G. (2001). "Product differentiation and upstream-downstream relations". Journal of Economics $\&$ Management Strategy, 10(2):201-233.

Ronnen, U. (1991). "Minimum quality standards, fixed costs, and competition". The RAND Journal of Economics, 22(4):490-504.

Salinger, M. (1991). "Vertical mergers in multi-product industries and edgeworth's paradox of taxation". The journal of industrial economics, pages 545-556.

Salinger, M. A. (1988). "Vertical mergers and market foreclosure". The Quarterly Journal of Economics, 103(2):345.

Shaked, A. and Sutton, J. (1982). "Relaxing price competition through product differentiation". The Review of Economic Studies, 49(1):3-13.

Shaked, A. and Sutton, J. (1983). "Natural oligopolies". Econometrica, 51(5):1469-1483.

Spengler, J. J. (1950). "Vertical integration and antitrust policy". Journal of Political Economy, 58:347-352.

Wauthy, X. (1996). "Quality choice in models of vertical differentiation". The Journal of Industrial Economics, 44(3):345-353.

Zenger, H. (2009). "Successive monopolies with endogenous quality". Working paper, Munich Personal RePEc Archive, pages 1-29. 